\title{
Insulin deficiency and insulin resistance in the pathogenesis of NIDDM: is a divorce possible?
}

\author{
E. Cerasi \\ Department of Endocrinology and Metabolism, Hebrew University Hadassah Medical Centre, Jerusalem, Israel
}

It is astonishing, even saddening, that after decades of intensive investigation it is still a matter of controversy whether a beta-cell defect or a defective insulin action is the main pathogenic mechanism in insulin-dependent diabetes mellitus (NIDDM) [1-4]. Categoric statements as to the primacy of one or other defect have engrossed the bibliography of many distinguished diabetologists (including yours faithfully). The controversy may have not been futile since it has promoted intensive research into the mechanisms of insulin secretion and of insulin action. Yet, we still seem relatively far from fully understanding the cell biological events, not to mention the molecular ones, that lead to loss of control over glucose homeostasis. The difference with the advances made in the pathogenesis of insulin-dependent diabetes (IDDM) is striking. Barring the option that only second-rate scientists were attracted to NIDDM (an option refused by my logic and instinct of preservation alike!), either more complex interactions are at play in the genesis of NIDDM, or a systematic error exists in our approach to investigate the regulation of glucose homeostasis.

Can insulin deficiency or insulin resistance, alone, produce NIDDM? This is a rhetorical question, since a minimal knowledge of physiology dictates that to keep glucose metabolism normally insulin must not only be present, but also be able to exert its action. Thus, if extreme ends are considered, pancreatectomized patients or lean patients with severe

Corresponding author: Prof. E. Cerasi, Department of Endocrinology and Metabolism, Hadassah University Hospital, 91120 Jerusalem, Israel

Abbreviations: NDDM, non-insulin-dependent diabetes mellitus; IDDM, insulin-dependent diabetes mellitus; IGT, impaired glucose tolerance; CSII, continuous subcutaneous insulin infusion; IRI, immunoreactive insulin
NIDDM need only insulin replacement, whereas in leprechaunism and other severe insulin receptor disorders no amount of insulin can correct the metabolic defect. The difficulty arises when less extreme reductions in insulin secretion and in insulin action are considered.

The distribution of the insulin response to glucose as well as that of sensitivity to insulin is remarkably widely ranged in the normal population [4-7]. In obese subjects, although insulin response is higher while insulin sensitivity is reduced, variability is as large, and considerable overlap exists with the values found in lean subjects. Thus, there exist substantial numbers of subjects with either a markedly low insulin response or low sensitivity to insulin, who nevertheless retain a normal glucose tolerance. For such subjects to become diabetic, we must assume that the reduced function (be it insulin secretion or insulin action) further deteriorates with time until a critical (extreme) level is reached, which by itself may be sufficient to induce glucose intolerance. The alternative is that, with time, other factors are added to reduced insulin secretion or to diminished insulin action, tipping the balance towards diabetes. (I apologize to the older readers of Diabetologia, who may experience a sense of déjà vu; I expressed similar views more than 25 years ago [8])

Does insulin resistance progress steadily during the transition from the normal state to impaired glucose tolerance (IGT) and NIDDM? Age and increased obesity reduce the whole body insulin sensitivity. However, subjects with IGT are often as insulin resistant as mild NIDDM patients; furthermore, in the healthy offspring of NIDDM patients insulin resistance of comparable magnitude to that found in IGT has been demonstrated [9]. Nevertheless, longitudinal studies on the evolution of insulin resistance are scarce, and it cannot be excluded that refinement in methodology for quantifying its severity may unravel 
progressive deteriorations that may have pathophysiological significance. The present For debate being on the role of the beta-cell, this topic will not be further elaborated; the interested reader is referred to a recent For debate in Diabetologia on the insulin resistance syndrome [10-13], and to a recent review [14]. One clinical comment still seems appropriate; NIDDM patients present major insulin resistance when evaluated by the hyperinsulinaemic normoglycaemic clamp technique, performed after acute normalization of blood glucose by insulin infusion. Since their insulin resistance is mainly of the "post-receptor" type, even suprapharmacological levels of insulin fail to normalize whole body glucose uptake. This suggests to the clinician that insulin treatment may be grossly inefficient in such patients. We were therefore surprised to find that continuous subcutaneous insulin infusion (CSII) was highly efficient in NIDDM [15]: excellent glycaemic control could be obtained in newly-diagnosed, diet-resistant, mildly obese NIDDM patients with daily insulin doses in the order of $0.6-0.8 \mathrm{IU} / \mathrm{kg}$, which is not different from the CSII doses utilized in insulin-deficient IDDM. Therefore, in contrast to what is commonly believed, the extent to which the results of acute clamp experiments have implications for understanding the chronic regulation of blood glucose in diabetes may be questioned; caution is certainly mandatory before drawing conclusions on therapeutic choices.

Plasma insulin and beta-cell function. Except in its most severe forms, both fasting plasma insulin and its fluctuating levels throughout the day are normal or higher than normal in NIDDM. This is the observation that has provided the rationale for insulin resistance in diabetes: if blood glucose remains high despite substantial levels of insulin, the hormone action must be defective. This is obviously a static view of a highly dynamic regulatory system, confusing cause and effect: what are "substantial" levels of insulin, what degree of hyperinsulinaemia is adequate for a given degree of hyperglycaemia? Glucose vs insulin dose-response curves have been constructed from data obtained in acute experiments [16]; however, data on long-term induced hyperglycaemia in normal subjects do not exist, therefore no normogramme can be established that would allow us to determine whether a given plasma insulin value in a given diabetic patient is higher or lower than normal. To the clinical endocrinologist this is a familiar difficulty: under the drive of high adrenocorticotrophic hormone (ACTH) levels, a patient with partial adrenal insufficiency may show "normal" cortisol levels during stress; this neither implies ACTH resistance at the level of the adrenals, nor exonerates the patient from developing Addisonian crisis. Such considerations lead me to the conclusion that, in the hyperglycaemic patient, I cannot assess whether the plasma insulin le- vel is high, normal or low; hence, from the daily blood glucose and plasma insulin levels I cannot evaluate whether beta-cell function is normal or abnormal.

Is the situation simpler in IGT, where only minor postprandial hyperglycaemia exists? Indeed not, since these subjects are often obese and insulin resistant. Insulin resistance, described in its simplest terms, obviously leads to augmented glycaemic stimulation of the beta-cell, since blood glucose is less reduced per unit hormone released. (This differential in blood glucose elevation is probably too small to be measured since it occurs gradually and is rapidly dampened by a compensatory increase in insulin secretion. A similar situation exists in most hormonal feed-back regulations; e.g. the elevation of gonadotropins early in menopause before measurable reduction in plasma oestrogen). The magnitude of this glycaemic "overdrive" of the beta-cell being a matter of estimation, it is impossible to assess the adequacy of the insulin response in a given context of insulin resistance. Attempts have been made to correlate quantitatively the insulin response to insulin sensitivity $[6,7,17]$; we are however far from having at our disposal normogrammes easily applicable to clinical and epidemiological assessments of beta-cell function in subjects with a wide spectrum of insulin sensitivity (compare with the situation of parathyroid hormone/plasma $\mathrm{Ca}^{2+}$ or aldosterone/urinary $\mathrm{Na}^{+}$; these can be found in standard endocrinology textbooks!).

A further cause for conceptual confusion has its source in the complexity of the mechanisms by which glucose leads to insulin secretion, where interactions between stimulatory and inhibitory events dictate the phasicity of the release [18]. In the context of the present discussion one of these is of paramount importance: time-dependent potentiation of insulin release. Indeed, prolonged stimulation with glucose induces a state of potentiation in the islet, which with time amplifies the insulin response, the degree of amplification reaching $200-400 \%$ under some conditions [18-20]. Consequently, plasma insulin levels measured early or late, for example during an oral glucose tolerance test (OGTT), may convey quite different informations on beta-cell function if this mechanism is ignored. A striking example of such an error is the bell-shaped insulin curve often used by epidemiologists to describe changes in beta-cell function seen during the reduction of glucose tolerance from normal to IGT and NIDDM [1]. This is an artefactual construction due to the use of 120 -min plasma insulin values in OGTT: patients with IGTwho have higher blood glucose levels throughout the test generate a strong signal for potentiation at a time when blood glucose is still high enough to stimulate insulin secretion; the resulting synergism induces the typical late insulin peak. (The results are similar when the area under the insulin curve is plotted since the increasing 
late peak values predominate). Also diabetic patients induce time-dependent potentiation [21]; however, in the face of a reduced secretory capacity, plasma insulin levels at $120 \mathrm{~min}$ are usually lower than in IGT but higher than in normal subjects. As shown earlier [22], and emphasized anew by Hales [3], if early (30-min) time-points are chosen, the insulin response to OGTT shows a linear fall from normal over IGT to NIDDM. Thus, provided the plasma insulin data is interpreted with full reference to the physiology of insulin secretion, it becomes clear that beta-cell responsiveness to glucose is lower than normal in IGT, and more so in NIDDM [23]. In fact, the recent interest in elevated secretion of proinsulin-related peptides in diabetes $[3,24]$, whilst important for the fasting immunoreactive insulin (IRI) levels, does not add much to the above discussion, since the decrease of total plasma IRI in IGT and NIDDM, corrected for blood glucose level and time of stimulation, is of such magnitude that an increase in the proportion of proinsulin is of little relevance.

Amplifiers of insulin release. In his For debate paper W.S. Zawalich rightfully draws attention to agents that amplify the release of insulin (other than the time-dependent potentiating effect of glucose), concentrating on cholinergic agonists, a topic that has interested him for considerable time. Indeed, cholinergic stimulation results in major amplification of insulin release, provided the beta-cell is already stimulated by glucose [25], an action similar in kinetic terms to that of gut hormones (incretins, e. g. GLP-1 $[26,27])$. This synergism may be of formidable magnitude; as an example during OGTT, when both vagal and incretin actions prevail, plasma insulin increases exponentially in response to minute changes in blood glucose (we calculated that in normal man increase of the hyperglycaemic response from $\sim 7 \mathrm{mmol} / 1$ to $\sim 8 \mathrm{mmol} / 1$ may double the plasma insulin response [23]). However, the stand taken by Dr. Zawalich seems exaggerated when he regards cholinergic and other amplifiers as "more physiologic releasers than glucose", because glucose is a "poor" secretagogue in the physiologic range. It is true that, in vitro as well as in man, glucose-induced insulin release is saturated at the non-physiologic range of $20-50 \mathrm{mmol} / 1$, with $\mathrm{ED}_{50}$ values around 8$12 \mathrm{mmol} / \mathrm{l} \mathrm{[23]}$, but this is only an expression of the large redundancy with which the islet works (which is also true for the insulin stores that are far beyond any physiologic need). The sensitivity of insulin release in response to glucose is however exquisite: in man and in any sensitive physiologic in vitro preparation it can be demonstrated that basal release is responsive to reduction of glucose from $4-5 \mathrm{mmol} / \mathrm{l}$ to 2.5 and further to $\sim 1.5 \mathrm{mmol} / \mathrm{l}$, and distinct firstphase responses can be obtained with a pulse of $6.9 \mathrm{mmol} / \mathrm{l}$ glucose [28]. More important perhaps is the fact that neither cholinergic agents nor incretins can induce insulin release in the absence of nutrients such as glucose. Thus, the physiologic limiting step for induction of insulin secretion remains the glucose stimulus. This obviously does not detract from the importance of amplifiers, since a "physiologic" insulin response is simply the beta-cell response to the sum total of primary as well as amplifying signals. It is worth remembering, however, that synergistic interactions are like multiplications, similar results being obtained whether the multiplier or the multiplicand is increased. Thus, while it is legitimate to postulate, as does Dr. Zawalich, that increased cholinergic activity is the first step towards induction of beta-cell hyperresponsiveness, a minimal increase in blood glucose in the face of an unchanged vagal tonus leads to an identical result.

Beta-cell hyperresponsiveness first? Dr. Zawalich develops his thoughts regarding vagus-induced betacell hyperresponsiveness with the specific objective of explaining the initial events in the development of obesity and NIDDM. As recently reviewed by Jeanrenaud [29], in several rodents events initiated in the central nervous system lead to hyperinsulinaemia and obesity, in some hypersecretion of insulin clearly antedating (and probably explaining) obesity and insulin resistance. Does a similar, hyperinsulinaemia first, situation exist in human obesity? I am not aware of longitudinal studies where beta-cell hyperresponsiveness could be demonstrated in subjects who later became obese at a time when their insulin sensitivity was still normal. In studies performed in lean young adults we found some insulin responses that could be as high as those of obese subjects [5]; however none of these became obese in the follow-up.

More established is the view that prediabetic individuals are hyperinsulinaemic. This view stems from epidemiological studies where hyperinsulinaemia was found to be a risk factor for diabetes [2], and from the follow-up of high-risk subjects such as the offspring of connubial diabetic patients among whom those with initial insulin resistance and hyperinsulinaemia showed a higher incidence of IGT and diabetes in a follow-up lasting several decades [14, 30]. (It has to be stressed that another study [31] does not support these findings). Whilst the present view favours insulin resistance as the inherited primary event, Dr. Zawalich suggests that hyperresponsiveness of the beta-cell in insulin sensitive subjects, induced by cholinergic activation, is the initial event which secondarily leads to insulin resistance and, later, to NIDDM. What evidence exists for this suggestion? All clinical studies point to the coexistence of insulin resistance and hyperinsulinaemia; in fact in some studies hyperinsulinaemia ceases to be a diabetes risk factor when obesity and blood glucose levels are taken into consideration [32]. I believe much of 
this confusion has been caused by our inability to quantify the insulin secretion in relation to the subject's insulin sensitivity. As an example, in the Joslin prediabetes study, first-phase insulin response to glucose was either within normal limits or slightly above normal despite early insulin resistance [14]. This contrasts with the mean threefold increase of the insulin response found in equally insulin resistant non-diabetic obese subjects, or in women in third trimester pregnancy $[33,34]$.

Does this mean that what has been denominated beta-cell hyperresponsiveness in prediabetes is in fact hyporesponsiveness in relation to insulin resistance? The idea is attractive that a beta-cell unable to adapt its function to decreasing insulin sensitivity would eventually cause metabolic decompensation. The debate concerns the timing of the beta-cell deficiency, since there is consensus that in the overtly hyperglycaemic diabetic patient the beta-cell response is secondarily reduced. Dr. Zawalich views the chain of events under the assumption that beta-cell hyperresponsiveness persists until exhaustion occurs through "glucose toxicity". This is our point of divergence: I (and others $[35,36]$ ) claim that, studied with correct methodology, normoglycaemic IGT subjects present reduced insulin responsiveness to glucose. This is even more marked if first-phase insulin response is considered, suggesting that beta-cell function is impaired at a time when blood glucose is normal most of the day. (This is not the place to discuss the importance of the short-lasting first-phase insulin release for the glucose homeostasis under physiological conditions; it is sufficient to consider its reduction and/or absence as a sign of beta-cell dysfunction.) We have found a reduction in first-phase insulin response also in a population of lean, insulin sensitive, normal glucose tolerant subjects [5]. In these persons glucose tolerance, although well within normal limits, was significantly lower than in subjects with a high insulin response [37]. Low insulin responses were found also in children [38], which is not surprising in view of the significant heritability of the insulin response [39]. The incidence of IGT and NIDDM was 4.5-fold higher over a 5-15 year follow-up in subjects with initially low insulin responses $[40,41]$. One can hardly incriminate "glucose toxicity" for inducing low insulin responses in children and young adults at a time when they were strictly normoglycaemic. Can beta-cells be driven to exhaustion in the absence of hyperglycaemia? This is possible in vitro: we have obtained major desensitization of rat islet cultures by chronic exposure to cAMP-generating agents [42], and Dr. Zawalich shows similar results with cholinergic stimulation (see Fig. 2 in his For debate article). In contrast, it is doubtful whether this can be reproduced in vivo, where reduction of the beta-cell mass and exposure to glucose are usually prerequisites for inducing desensitization of the islet [43]. Among several natu- ral models, Dr. Zawalich cites the sand rat as support for his thesis, since this rodent develops nutrition-induced insulin resistance, obesity and diabetes. We have recently demonstrated, however, that once the sand rat is hyperglycaemic, most circulating IRI is in fact proinsulin-related peptides, the islets being severely depleted of insulin [44]; these events occur within days of weaning (Gadot et al., unpublished data). We therefore believe that a yet unidentified defect in the synthesis and/or handling of insulin in the beta-cell prepares the ground for the inability of the insulin secretion to cope with increased demand in this model of obesity/NIDDM. (See Note added in proof)

No one event first? The controversy of whether defective beta-cell function or defective insulin action constitutes the initial defect in the development of NIDDM will probably remain with us for some time, but the question is whether it really matters. Most evidence seems to indicate that reduced beta-cell responsiveness (with the caveats discussed above) and reduced insulin sensitivity go hand-in-hand from the very beginning. Both insulin secretion and insulin action are genetically controlled $[39,45]$ and/or influenced by intrauterine and neonatal factors [46, 47]. Both show considerable variation in the normoglycaemic population. It is in the logic of physiological regulatory loops that two variables such as insulin secretion and insulin action should vary inversely in a closely linked manner. The inability of one of them to fully follow changes in the other would generate a functional deficit which, if cumulative (e.g. over a prolonged period), could lead to IGT. One could suggest that we are simply observing the normal distributions of insulin secretion and of insulin action; the lower the secretion, the higher the insulin sensitivity has to be to maintain normal glucose homeostasis, and vice versa. Since extreme reduction in one function would necessitate extreme augmentation in the other, such subjects would indeed run a high risk of becoming diabetic. For less extreme reductions, beta-cell function and insulin action should be contemplated on a continuous scale of risks, where subjects combining low functions would run an inversely greater risk of decompensating for the glucose tolerance. My own biases make me ascribe greater weight to reduction in beta-cell function than to reduction in insulin action; nevertheless, the principle of combining quantitative risks remains unaltered. It should be re-emphasized that what is meant here by, e.g. insulin response is not given insulin values, but the range of responses that are within the capacity of the beta-cells of a given subject; thus, a low insulin responder is a subject whose range of responses is in the lower end of the distribution. Both regarding insulin production and insulin action, it seems reasonable to assume that subjects whose functional capac- 
ity is at the lower end of the spectrum would be more sensitive, in terms of diabetes susceptibility, to factors that further reduce the function (age, environmental toxins, amylin deposition [48], "glucose toxicity", etc. for the beta cell; age, obesity, decreased physical activity, etc. for insulin action).

If the pathogenesis of NIDDM is considered in the above terms of statistical risks related to quantitative changes in "functional capabilities", the quest should not be for a gene that controls a specific step in, e.g. beta-cell recognition of glucose (the glucokinase gene [49] example) but for genes that orchestrate the responsiveness and adaptability of the islet. These remain to be identified.

\section{References}

1. Groop LC, Widen E, Ferrannini E (1993) Insulin resistance and insulin deficiency in the pathogenesis of type 2 (non-insulin-dependent) diabetes mellitus: errors of metabolism or of methods? Diabetologia 36: 1326-1331

2. Taylor SI, Accili D, Imai Y (1994) Insulin resistance or insulin deficiency. Which is the primary cause of NIDDM? Diabetes 43: 735-740

3. Hales CN (1994) The pathogenesis of NIDDM. Diabetologia 37[Suppl 2]:S162-S168

4. Lillioja S, Mott DM, Spraul M et al. (1993) Insulin resistance and insulin secretory dysfunction as precursors of non-insulin-dependent diabetes mellitus. Prospective studies of Pima Indians. New Engl J Med 329: 1988-1992

5. Cerasi E, Luft R (1967) The plasma insulin response to glucose infusion in healthy subjects and in diabetes mellitus. Acta Endocr (Kbh.) 55: 278-304

6. Hollenbeck CB, Chen N, Chen Y-DI, Reaven GM (1984) Relationship between the plasma insulin response to oral glucose and insulin-stimulated glucose utilization in normal subjects. Diabetes 33: 460-463

7. Kahn SE, Prigeon RL, McCulloch DK et al. (1993) Quantification of the relationship between insulin sensitivity and $\beta$-cell function in human subjects. Evidence for a hyperbolic function. Diabetes 42: 1663-1672

8. Cerasi E, Luft R (1967) "What is inherited - what is added" hypothesis for the pathogenesis of diabetes mellitus. Diabetes 16: 615-627

9. Gulli G, Ferrannini E, Stern M, Haffner S, DeFronzo R (1992) The metabolic profile of NIDDM is fully established in glucose-tolerant offspring of two Mexican-American NIDDM parents. Diabetes 41: 1575-1586

10. Jarrett RJ (1994) Why is insulin not a risk factor for coronary heart disease? Diabetologia 37: 945-947

11. Reaven GM, Laws A (1994) Insulin resistance, compensatory hyperinsulinaemia, and coronary heart disease. Diabetologia 37: 948-952

12. Fontbonne A (1994) Why can high insulin levels indicate a risk for coronary heart disease? Diabetologia 37: 953-955

13. Stern MP (1994) The insulin resistance syndrome: the controversy is dead, long live the controversy! Diabetologia 37: 956-958

14. Kahn CR (1994) Insulin action, diabetogenes, and the cause of type II diabetes. Diabetes 43: 1066-1084

15. Ilkova H, Glaser B, Tunckale A, Bagriacik N, Cerasi E (1993) Induction of long-term glycaemic control in diet-resistant type 2 diabetic patients by two-week CSII treatment. Diabetologia 36[Suppl 1]:A76 (Abstract)
16. Cerasi E, Luft R, Efendic S (1972) Decreased sensitivity of the pancreatic beta-cells to glucose in prediabetic and diabetic subjects. A glucose dose-response study. Diabetes 21: 224-234

17. Hosker JP, Matthews DR, Rudenski AS et al. (1985) Continuous infusion of glucose with model assessment: measurement of insulin resistance and B-cell function in man. Diabetologia 28: 401-411

18. Nesher R, Cerasi E (1987) Biphasic insulin release as the expression of combined inhibitory and potentiating effects of glucose. Endocrinology 121: 1017-1024

19. Cerasi E (1975) Potentiation of insulin release by glucose in man. I. Quantitative analysis of the enhancement of glucose-induced insulin secretion by pretreatment with glucose in normal subjects. Acta Endocr (Kbh) 79: 483-501

20. Grill V, Adamson U, Cerasi E (1978) Immediate and timedependent effects of glucose on insulin release from rat pancreatic tissue: evidence for different mechanisms of action. J Clin Invest 61: 1034-1043

21. Cerasi E (1975) Potentiation of insulin release by glucose in man. III. Different sensitivities of the pancreas to the initiating and the potentiating actions of glucose in diabetic and prediabetic subjects. Acta Endocr (Kbh) 79: 511-534

22. Cerasi E, Efendic S, Luft, R (1973) Dose-response relationship of plasma insulin and blood glucose levels during oral glucose loads in prediabetic and diabetic subjects. Lancet I:794-797

23. Cerasi E (1992) Aetiology of type II diabetes. In: Ashcroft FM, Ashcroft SJH (eds) Insulin: molecular biology to pathology: a practical approach. Oxford University Press, Oxford, pp 347-392

24. Rhodes CJ, Alarcon C (1994) What $\beta$-cell defect could lead to hyperproinsulinemia in NIDDM? Some clues from recent advances made in understanding the proinsulin-processing mechanism. Diabetes 43: 511-517

25. Zawalich WS, Zawalich KC (1988) Phosphoinositide hydrolysis and insulin release from isolated perifused rat islets. Diabetes 37: 1294-1300

26. Thorens B, Waeber G (1993) Glucagon-like peptide-I and the control of insulin secretion in the normal state and in NIDDM. Diabetes 42: 1219-1225

27. Gutniak MK, Linde B, Holst JJ, Efendic S (1994) Subcutaneous injection of the incretin hormone glucagon-like peptide 1 abolishes postprandial glycemia in NIDDM. Diabetes Care 17: 1039-1044

28. Nesher R, Eylon L, Segal N, Cerasi E (1989) ß-Cell memory to insulin secretagogues: characterization of the timedependent inhibitory control system in the isolated rat pancreas. Endocrinology 124: 142-148

29. Jeanrenaud B (1994) Central nervous system and periferal abnormalities: clues to the understanding of obesity and NIDDM. Diabetologia 37 [Suppl 2]:S169-S178

30. Martin BC, Warram JH, Krolewski AS, Bergman RN, Soeldner JS, Kahn CR (1992) Role of glucose and insulin resistance in development of type 2 diabetes mellitus: results of a 25-year follow-up study. Lancet 340: 925-929

31. Johnston C, Ward WK, Beard JC, McKnight B, Porte D (1990) Islet function and insulin sensitivity in the non-diabetic offspring of conjugal type 2 diabetic patients. Diabetic Med 7: 119-125

32. McCance DR, Pettitt DJ, Hanson RL, Jacobsson LTH, Bennett PH, Knowler WC (1994) Glucose, insulin concentrations and obesity in childhood and adolescence as predictors of NIDDM. Diabetologia 37: 617-623

33. Nesher R, Della Casa L, Litvin Y, Sinai J, Del Rio G, Pevsner B, Wax Y, Cerasi E (1987) Insulin deficiency and insulin resistance in type 2 (non-insulin-dependent) diabetes. Quanti- 
tative contributions of pancreatic and peripheral responses to glucose homeostasis. Eur J Clin Invest 17:266-274

34. Edström K, Cerasi E, Luft R (1974) Insulin response to glucose infusion during pregnancy. A prospective study of high and low insulin responders with normal carbohydrate tolerance. Acta Endocr (Kbh) 75: 87-104

35. Porte D (1991) $\beta$-cells in type II diabetes mellitus. Diabetes 40: $166-180$

36. Hales CN, Barker DJP (1992) Type 2 (non-insulin-dependent) diabetes mellitus: the thrifty phenotype hypothesis. Diabetologia 35: 595-601

37. Cerasi E, Luft R (1972) The prediabetic state, its nature and consequences - a look toward the future. Diabetes 221 (Suppl 2):685-694

38. Cerasi E, Luft R (1970) The occurrence of low insulin response to glucose infusion in children. Diabetologia 6: 85-89

39. Iselius L, Lindsten J, Morton NE, Efendic S, Cerasi E, Haegermark A, Luft R (1985) Genetic regulation of the kinetics of glucose-induced insulin release in man - studies in families with diabetic and non-diabetic probands. Clin Genet 28: 8-15

40. Cerasi E (1985) A la recherche du temps perdu: epilogue to the Minkowski Award lecture 1974. Diabetologia 28: 547555

41. Efendic S, Luft R, Wajngot A (1984) Aspects of the pathogenesis of type 2 diabetes. Endocrinol Rev 5: 395-410

42. Kaiser N, Corcos AP, Sarel I, Cerasi E (1991) Monolayer culture of adult rat pancreatic islets on extracellular matrix: modulation of B-cell function by chronic exposure to high glucose. Endocrinology 129: 2067-2076

43. Leahy JL, Bonner-Weir S, Weir GC (1992) $\beta$-cell dysfunction induced by chronic hyperglycemia. Diabetes Care 15: $442-455$
44. Gadot M, Leibowitz G, Shafrir E, Cerasi E, Gross DJ, Kaiser N (1994) Hyperproinsulinemia and insulin deficiency in the diabetic sand rat (Psammomys obesus). Endocrinology 135: $610-616$

45. Martin BC, Warram JH, Rosner B, Rich SS, Soeldner JS, Krolewski AS (1992) Familial clustering of insulin sensitivity. Diabetes 41: 850-854

46. Phillips DIW, Hirst S, Clark PMS, Hales CN, Osmond C (1994) Fetal growth and insulin secretion in adult life. Diabetologia 37: 592-596

47. Phillips DTW, Barker DJP, Hales CN, Hirst S, Osmond C (1994) Thinness at birth and insulin resistance in adult life. Diabetologia 37: 150-154

48. Lorenzo A, Razzaboni B, Weir GC, Yankner BA (1994) Pancreatic islet cell toxicity of amylin associated with type-2 diabetes mellitus. Nature 368: 756-760

49. Matschinsky F, Liang Y, Kesavan P et al. (1993) Glucokinase as a pancreatic $\beta$ cell glucose sensor and diabetes gene. J Clin Invest 92: 2092-2098

50. Leiter EH, Carroll R, Steiner DF, Fricker F (1995) Defects in insulin processing mediated by the fat mutation in mice. Diabetes 44 [Suppl 1] 42 A (Abstract)

Note added in proof: That this belief is correct has recently been demonstrated in another model, the C57BL/KsJ-fat/fat mice. These "hyperinsulinaemic", hyperglycaemic animals in fact have a mutation in carboxypeptidase $H$, resulting in the production of diarginyl insulin (and secondary hyperproinsulinaemia); therefore the circulating insulin-like peptides show low biological activity, explaining the hyperglycaemia of the animals [50]. 